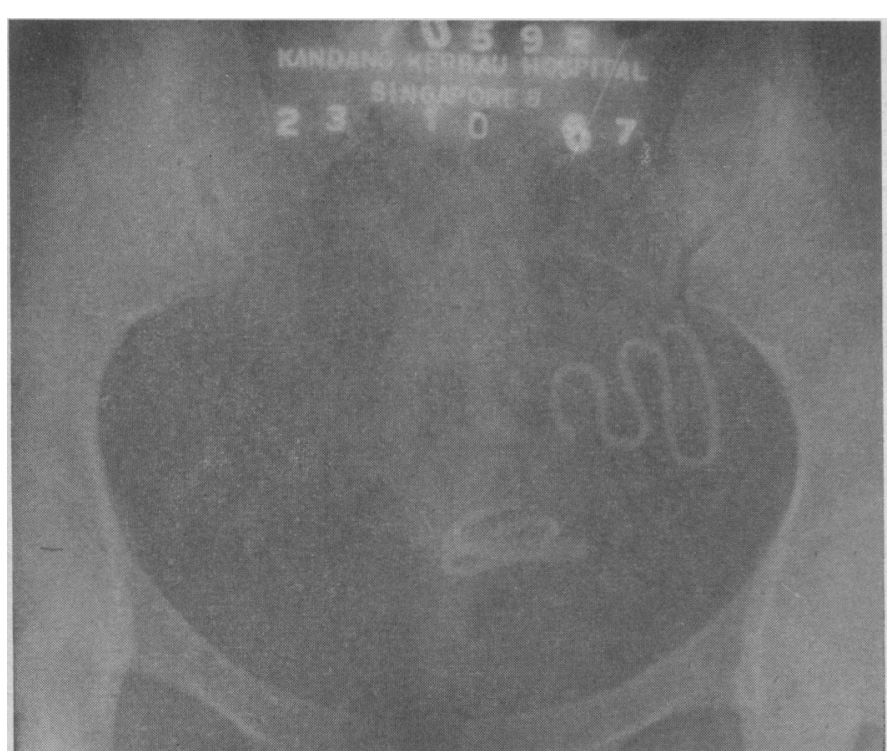

FIG. 1

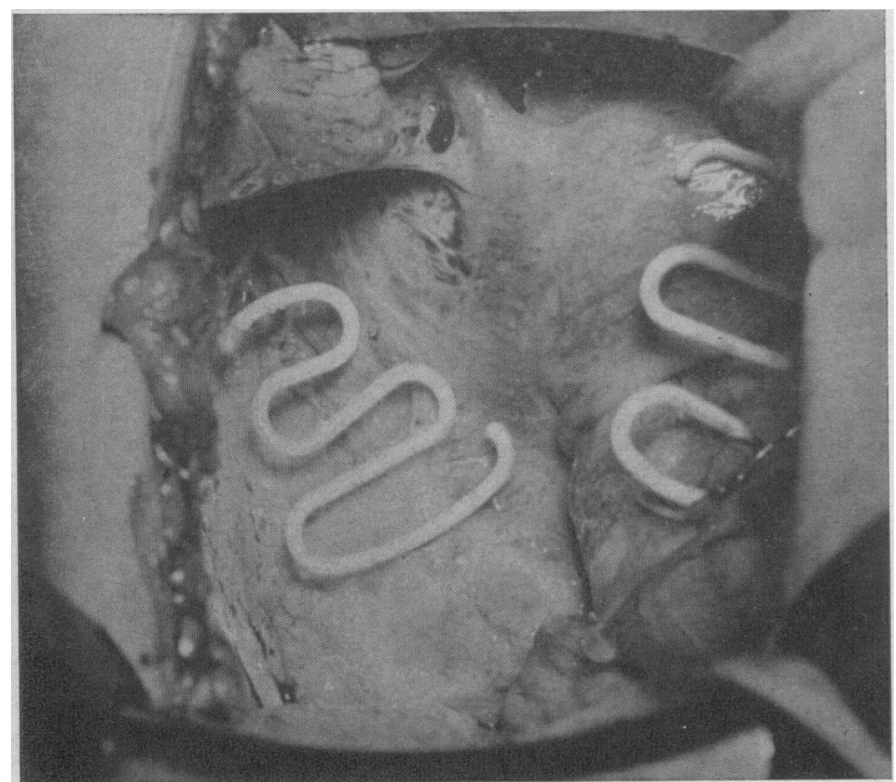

Fig. 2b

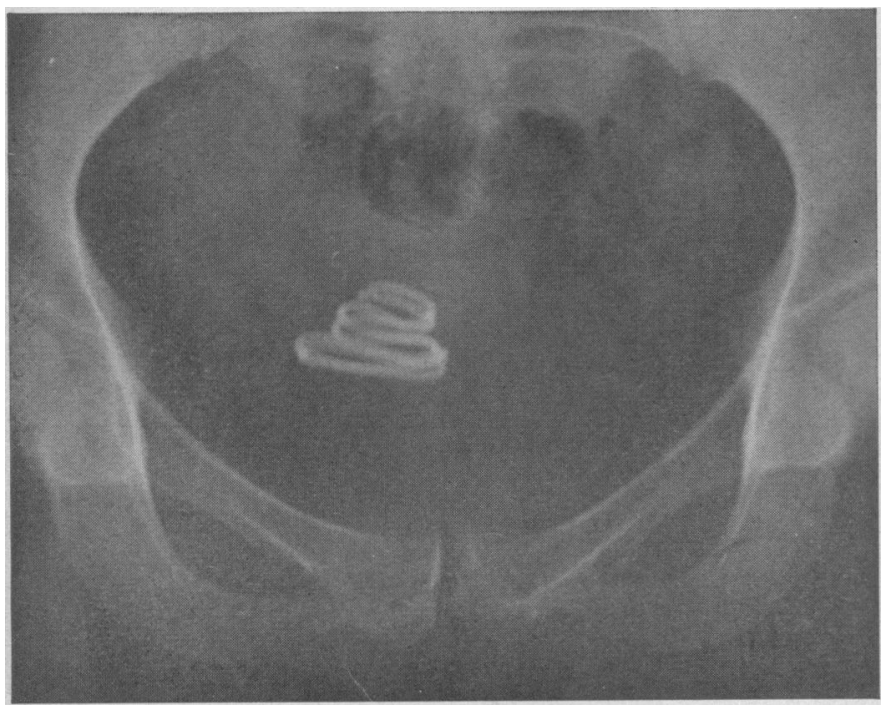

Fig. 3a

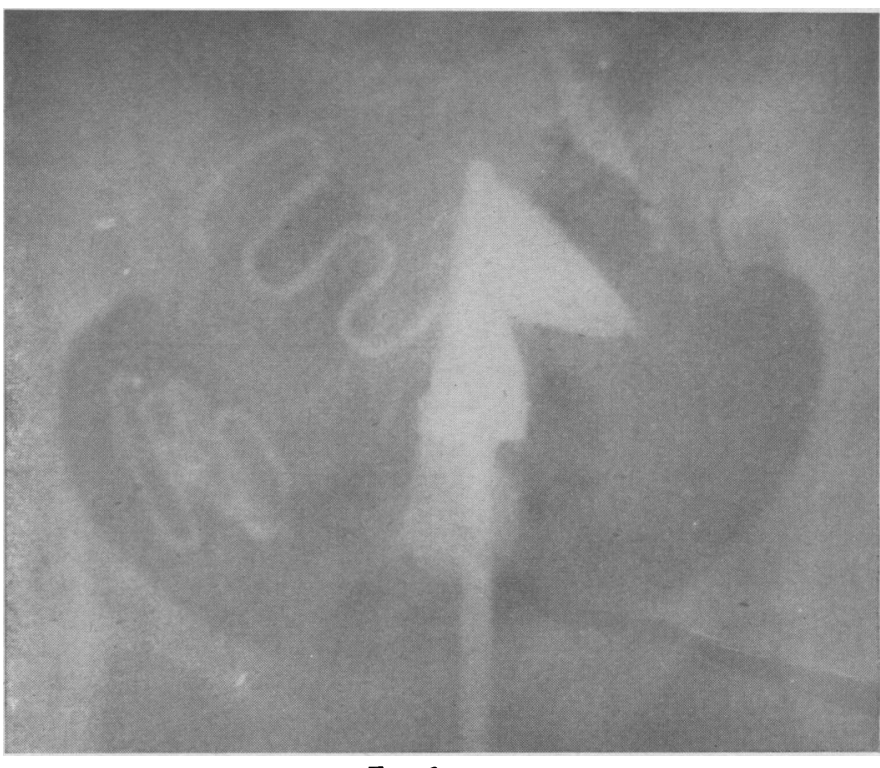

FIG. 2a

Fig. 1.- One loop in the uterine cavity which was subsequently removed and the second loop outside the uterine cavity.

Fig. 2a.-Hysterosalpingogram showing two loops outside the uterine cavity.

FIG. 2b.-Two loops lying free in the peritoneal cavity at laparotomy.

FIG. 3a.-Two loops in the uterine cavity.

FIG. 3b.-Two loops connected to one another after removal from within the uterine cavity. 
titre subsequently fell. In Case 1 a titre of $1: 80$ was noted at 61 days, and this had fallen to $1: 20$ at 114 days. In Case 2 the test was not made until a year had elapsed, by which time the titre of 1:20 obtained was reported as consistent with a past infection. In Case 4 the complement-fixation test was still negative at 23 days, shortly after which time she defaulted. However, this could well have become positive later.

During the period during which these cases were encountered a further patient with severe unequivocal vulvar herpes was seen. She was a 21-year-old woman who also developed a high fever of $103.4^{\circ}$ F. $\left(39.7^{\circ}\right.$ C.), drowsiness, and headache; a lumbar puncture was required to exclude complicating encephalitis. Four months later there was a recurrence of the herpes on her vulva. In this case repeated complement-fixation reactions for herpes simplex were negative at $1,2,5,12$, and 21 days from first attendance.

\section{Summary and Conclusions}

Six cases of a strikingly unusual necrotic cervicitis of great severity in young women are described. Symptoms included vaginal discharge in all cases; some had dysuria, which in one case was severe enough to require catheterization; and some complained of lower abdominal pain. The onset was acute or subacute with evidence of fever, which was high in one patient. The affected cervices were white and necrotic, particularly around the os, bled very easily, and were in some cases tender to the touch or on movement. Gonorrhoea, salpingitis, leucoplakia, carcinoma, and the effects of cautery were all at one time considered in the diagnosis.
Tests for gonorrhoea, syphilis, and trichomoniasis were consistently negative. A bacterial swab from the cervix might or might not show faecal organisms; the cervical cytology was unsuitable, requiring the examination to be repeated because the specimen was either too haemorrhagic or contained severely inflamed cells. The white cell count was not raised (range $4,000-6,000 / \mathrm{cu}$. mm.) but a consistent positive finding was a raised sedimentation rate $(15-40 \mathrm{~mm}$. in one hour).

The cervix healed slowly and the white core-like slougb around the cervical os and involving the endocervix persisted usually for more than seven days, but complete healing occurred in the majority of cases during the third week.

The cases indicate that necrotic cervicitis may be associated with other herpetiform lesions in the anogenital area or may exist alone. The male consort may show herpetiform lesions at or before the time the condition is diagnosed in the female.

The pattern of results of the complement-fixation test for herpes simplex in these cases was for the reaction to be negative at the time the cervicitis was severe but to become positive at a titre of $1: 40$ to $1: 80$ in the third week as the cervix was healing. Seropositivity once present may apparently persist at a high level for two or more months, after which time there is a tendency for the titre to fall to a lower level but still to be detectable a year later.

Primary infection with herpes simplex can be a serious sexual hazard for the young woman, resulting sometimes in an acute illness necessitating admission to hospital.

Gratitude is expressed to Professor K. R. Dumbell for kindly undertaking the serological investigations for herpes simplex.

\title{
Translocation of Lippes Loop (The Missing Loop)*
}

\author{
S S. RATNAM,† F.R.C.S., F.R.C.S.ED., F.R.C.s.glASG., M.R.C.o.G. ; J. C. K. YIN, $\ddagger$ M.B., B.S., D.M.R.D
}

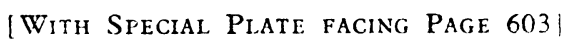

The use of intrauterine contraceptive devices for fertility control is on the increase. At the Second International Conference sponsored by the Population Council in October 1964 it was estimated that more than 100,000 women were wearing the Lippes loop. Since then many more countries have taken part in the international programme for population control, and in some of them the loop has displaced all other methods of family planning. The number of women wearing the loop must be very much greater than that reported in 1964 . Various modifications of the old Grafenberg ring-Hall and Stone, 1962 ; Lippes, 1962 ; Margulies, 1962 ; Birnberg and Burnhill, 1964 -have been made available for mass insertion in national family planning programmes. Of the various forms of plastic devices the Lippes loop was chosen by the Population Council because of the simplicity of its insertion and removal, and the minimal side-effects and complications. The greatest advantage of the devices with a cervical appendage like the spiral and the loop is the simplicity in which their presence and proper position within the uterine cavity can be confirmed. However, the tail

- This study was conducted by the Joint University/Government I.U.C.D. Project Committee. The members of the Committee are : Prof essor
S. H. Tow (chairman), Mr. T. H. Lean, Dr. S. M. Goon, Dr. D. S. H. Tow (chairman), Mr.
Wolfers, Mr. S. S. Ratnam.

t Lecturer, Department of Obstetrics and Gynaecology, University of

‡ Radiologist, General Hospital, Singapore of a Lippes loop may disappear if it works its way into the uterine cavity, myometrium, abdominal cavity, or endocervix; when the loop is expelled without the patient's knowledge ; or when the loop is inserted direct into the peritoneal cavity through a uterine perforation.

Though translocation or uterine perforation has been recorded by many workers (Table I) the incidence reported by those carrying out large-scale insertions has been very low. The incidence for the Lippes loop is stated to be about $0.6 / 1,000$ (Tietze, 1965). However, a study of 8,977 insertions carried out at the Kandang Kerbau Hospital, Singapore, by a Joint University/Government Committee showed an incidence of $0.87 \%$, or $8.7 / 1,000$ - much greater than that reported by other workers. The study included post-partum women who had their babies at the hospital between October 1965 and July 1966. Women who accepted the loop were given the choice of having it before they were discharged from the hospital or on their postnatal visit four to eight weeks later. A total of 3,168 loops were inserted in the immediate post-partum period and 5,809 in the delayed post-partum period (Table II). More than $90 \%$ of the immediate post-partum insertions were performed in the first 48 hours after delivery. All insertions were carried out by doctors who had some experience in gynaecology or who had been specially trained to insert the loops. The patients wire instructed to feel for the nylon threads at frequent 
intervals, especially after menstrual periods and coitus. They were asked to report at the clinic if they failed to feel the thread. The patients were seen for the first time four weeks after insertion and subsequently at 16,40 , and 88 weeks. Letters were sent to defaulters. At present a home-visiting survey is being conducted to contact the defaulters who failed to respond to letters.

Tabla I.-Uterine Perforations Reported in the Literature up to End of 1966

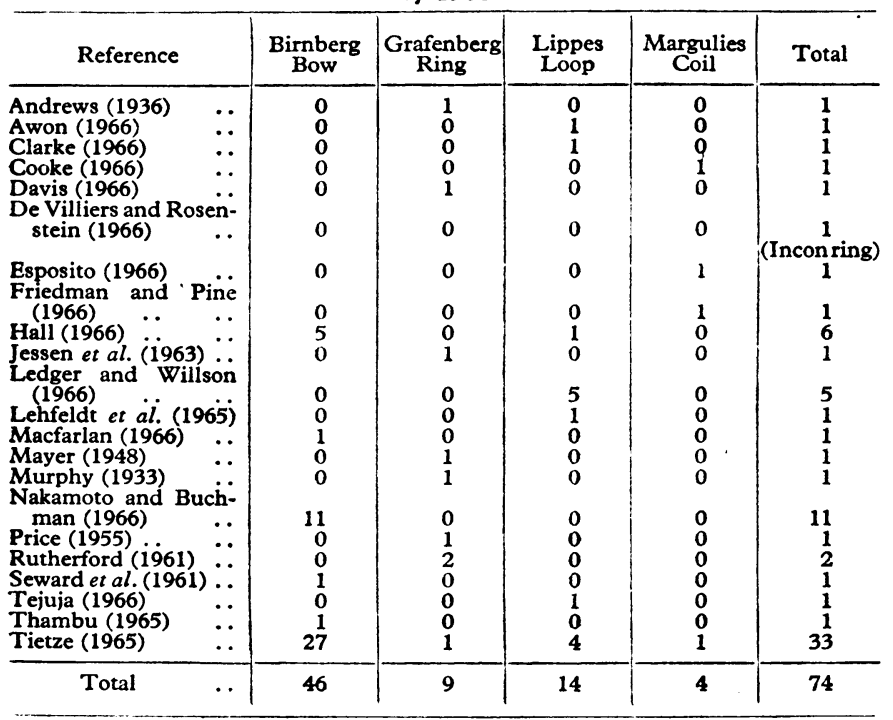

TABLE II.-Incidence of Translacation in 8,977 Cases

\begin{tabular}{|c|c|c|c|}
\hline $\begin{array}{l}\text { Period of Post-partum } \\
\text { Insertion }\end{array}$ & $\begin{array}{l}\text { No. of } \\
\text { Insertions }\end{array}$ & $\begin{array}{l}\text { No. of } \\
\text { Translocations }\end{array}$ & $\begin{array}{c}\text { Rate } \\
\text { per } 100\end{array}$ \\
\hline $\begin{array}{c}\text { Within } 1 \text { week } \\
\text { within } 48 \text { hours }) \\
4 \text { to } 8 \text { weeks }\end{array}$ & $\begin{array}{l}3,168 \\
5,809\end{array}$ & $\begin{array}{r}4 \\
74\end{array}$ & $\begin{array}{l}0.12 \\
1.3\end{array}$ \\
\hline Total .. & 8,977 & 78 & 0.87 \\
\hline
\end{tabular}

\section{Diagnosis}

At the follow-up visits any abnormal symptoms were noted and a vaginal examination was made of each patient. If the nylon threads of the Lippes loops were not seen the following investigations were carried out: (a) careful palpation of the vaginal fornices, especially adjoining the uterus for the possibility of translocated loops; (b) exploration of the uterine cavity, as an outpatient procedure, with the Beolocator or with a Novak curette (Ratnam and Yin, 1968); (c) plain $x$-ray examination of the abdomen; (d) hysterosalpingography ; and (e) laparotomy/colpotomy/vaginal hysterectomy

\section{Results}

A total of 8,977 insertions were performed during this period; 3,168 were early post-partum insertions and 5,809 delayed post-partum insertions. There were four translocations in the immediate post-partum series and 74 in the late postpartum series. The diagnostic methods used in the 78 cases are shown in Table III. In 72 out of the 78 cases the diagnosis was made with the help of a plain $x$-ray film of the pelvis and on exploration of the uterine cavity either with a Beolocator or with a Novak curette. Hysterosalpingograms were performed in 30 patients. Seventeen patients had laparotomies and five

TaBlB III.-Diagnostic Methods Used

Clinical (loop palpable in fornices)

Clinical (loop palpable in fornices)
Beolocator/Novak curette $+x$-ray examination
Hysterosalpingogram

Laparotomy

Colpotomy/vaginal hysterectomy had either a colpotomy or vaginal hysterectomy and removal of the loop.

\section{Discussion}

$\underline{\underline{T}}$

With renewed interest and widespread acceptance of the $\frac{3}{D}$ intrauterine contraceptive device, complications associated with $\odot$ their use will increase. Minor, though annoying, complaints such as prolonged menses, irregular bleeding, abdominal cramps, $\overrightarrow{\bar{N}}$ expulsion, and leucorrhoea have been extensively reported and have been accepted as complications that would not interfere $\bar{D}$ with the continued popularization of the Lippes loop. Trans- $\bar{\omega}$ location of the loop, though a relatively uncommon complica- $\overline{\mathrm{D}}$ tion, has not been stressed, and in fact has not been known to many workers in this field-so much so that it failed to draw on their attention when the nylon threads had disappeared from $\overrightarrow{0}$ the vagina. There have been only a few scattered reports. The $\overrightarrow{\vec{H}}$ translocation rate in the present series to date has been $8.7 / \vec{\omega}$ 1,000 and is likely to increase as more cases of perforation from $\bar{\partial}$ the initial insertions of 8,977 cases are subsequently discovered. This is very much higher than the reported figures in the $\vec{i}$ literature (Tietze, 1965; Hall, 1966 ; Ledger and Willson, of 1966) and also in unreported observations of similar projects $\stackrel{N}{N}$ carried out in other countries (A. P. Satterthwaite, personal communication, 1966 ; G. I. Zatouchni, personal communica- $\vec{N}$ tion, 1966).

Suspicion of translocation was usually aroused when the $\varphi$ nylon threads were not felt or had shortened considerably. In about a third of the cases the patients had requested removal, $\bar{\supset}$ but traction of the threads failed to dislodge the loop and suspicion of translocation arose. All these patients were sub- $\overrightarrow{\mathscr{O}}$ jected to a complete examination to exclude perforation. The 9 fornices were carefully palpated and the uterine cavity was explored, and if found to be empty a plain $x$-ray examination of the abdomen was carried out. The diagnosis was confirmed either with a hysterosalpingogram or with a laparotomy, unless the loop was easily felt in the fornices. In no case was it $\mathbb{D}$ assumed that the loop could have been expelled without the $\vec{F}$ patient's knowledge. It has been the experience of workers here that if the guide threads are missing it is much more likely that the threads have disappeared into the uterine cavity or the loop had translocated through the uterine wall rather than for the loop to have been expelled without the patient's knowledge. One of us (S.S. R.) has seen two patients with one loop in the peritoneal cavity and another in the uterine cavity (Special Plate, Fig. 1), one patient with two loops in the peritoneal cavity (Figs. $2 \mathrm{a}$ and $2 \mathrm{~b}$ ), and another patient with two 8 loops within the uterine cavity with no visible threads (Figs. 3a and $3 b$ ).

The follow-up rate of this study was $70 \%$, and all complica- N tions have been seen by S.S. R. The high rate of perforation met with could be due to one of three reasons: (1) faulty technique, (2) too large a loop for possibly smaller Asian uteri, and (3) awareness of the possibility of this complication and $\mathrm{N}$ therefore better and more thorough methods of diagnosis. The $\omega$ first of these is highly unlikely, because all insertions were carried $\underset{7}{ }$ out by trained medical personnel, whereas in many countries 0 insertions are performed by paramedical personnel. The second $\mathbb{D}$ reason is only a possibility, but the incidence of translocation in other Asian countries in women of the same ethnic group - for example, Hong Kong, Taiwan, India, and Pakistanhas either been low or not reported. The most likely explanation for the low rates of perforation reported in the literature $\mathbb{Q}$ is failure to recognize the complication because of poor followup or inadequate investigation.

To conclude, we wish to stress that when the patient is unaware of the expulsion of the loop, and the nylon threads are missing, the chances are that the loop is still within the uterine cavity, warranting a thorough examination and investigation to exclude translocation of the loop. Translocation of the Lippes loop is not as uncommon as is reported in the literature. 
Better follow-up, increased awareness of the possibility of this complication, and more complete investigation will no doubt reveal a higher incidence.

\section{Summary}

There were 8,977 first insertions of the Lippes loop ; 3,168 were inserted before the patients went home and 5,809 at the postnatal visit.

The incidence of translocation was $8.7 / 1,000$, about 15 times that reported by other investigators.

The low rate of translocation reported by others is due either to unawareness of this complication or to inadequate methods of diagnosis.

We wish to thank the chairman and members of the Joint University/Government I.U.C.D. Project Committee and the chairman and members of the Singapore Family Planning and Population Board for their co-operation and permission to publish these figures. We also wish to thank the doctors who participated in the I.U.C.D. programme for referring the cases to us, and $\mathrm{Mr}$. Anthony Khoo for the photography and secretarial work.
REFERENCES

Andrews, C. J. (1936). f. Amer. med. Ass., 107, 279

Awon, M. (1966). F. Obstet. Gynaec. Brit. Cwlth, 73, 858

Clarke, J. P. (1966). Amer. F. Obstet. Gynec., 94, 285.

Cooke, B. J. E. (1966). Brit. med. F., 1, 1236.

Davis, H. (1966). Obstet. gynec. Surv., 21, 491. Gynec., 96, 592

Esposito, J. M. (1966). Obstet. and Gynec., 28, 799.

Friedman, P. J., and Pine, H. L. (1966). Obstet. and Gyncc., 27, 814

Hall, R. E. (1966). Amer. F. Obstet. Gynec., 94, 65.

Jessen, D. A., Lane, R. E., and Green, R. R. (1963). Amer. F. Obstes Gynec., 85, 1023.

Ledger, W. J., and Willson, J. R. (1966). Obstet. and Gynec., 28, 806.

Lehfeldt, H., Kulka, E. W., and Liebmann, H. G. (1965). Obstet. and Gynec., 26, 679 .

Macfarlan, S. M. (1966). Amer. F. Obstet. Gynec., 94, 283.

Mayer, H. H. (1948). Chin. med. f., 66, 212.

Mayer, H. H. (1948). Chin. med. f., 66,

Murphy, M. C. (1930. Amer. Y. Obstet. Gynec., 94, 1073.

Price, C. W. R. (1955). Med. F. Aust., 1, 106.

Ratnam, S. S., and Yin, J. C. K. (1968). Proceedings of the Malaysian Congress of Medicine. To be published.

Rutherford, A. M. (1961). N.Z. F. Med., 60, 413.

Seward, P. J., Burns, G. T., and Quattlebaum, E. G. (1961). F. Amer med. Ass., 194, 1385

Tejuja, S. (1966). Brit. med. f., 2, 1390

Thambu, J. (1965). Brit. med. F., 2, 407

Tietze, C. (1965). Sixth Progress Report, Part I. National Committee on Maternal Health, New York, 31 December 1965.

\title{
Asbestos Bodies in Routine Necropsies on Tyneside : a Pathological and Social Study
}

\author{
THOMAS ASHCROFT,* M.B., CH.B.
}

Brit. med. I., 1968, 1, 61 $4-618$

An association between inhalation of asbestos dust and the development of diffuse mesothelioma of pleura was first suggested by Wagner, Sleggs, and Marchand (1960) in South Africa. Further studies in South Africa, Britain, and elsewhere have provided confirmatory evidence and have also shown that the peritoneum may react in a similar way (Thomson, 1962 ; Hourihane, 1964 ; Enticknap and Smither, 1964 ; Owen, 1964 ; Elmes, McCaughey, and Wade, 1965 ; Selikoff, Churg, and Hammond, 1965). In many cases evidence of only brief exposure to asbestos has been found. In a series of cases of mesothelioma Thomson (1962) found evidence of limited asbestosis in the lung bases of many subjects with no known bistory of occupational exposure to asbestos and went on to investigate the incidence of asbestos bodies in lung smears at routine necropsies in Cape Town, finding bodies in over $25 \%$ of cases. Subsequent studies of lung smears in other cities have shown an incidence ranging from 27 to $47 \%$ of cases (Thomson and Graves, 1966 ; Cauna, Totten, and Gross, 1965 ; Anjilvel and Thurlbeck, 1966 ; Roberts, 1967). Asbestos bodies have also been found in histological sections of lung tissue from routine necropsies, with an incidence ranging from $6 \%$ (Hourihane, 1964) to $58 \%$ (Meurman, 1966).

The present analysis of the frequency of asbestos bodies in the lung at routine necropsy was undertaken in association with a survey of cases of mesothelioma in the major shipbuilding area of Tyneside. The objects of the study were to ascertain the incidence of asbestos exposure in the population served by the Royal Victoria Infirmary in Newcastle upon Tyne ; to trace, if possible, the source of any asbestos found; and to use the results as a control with which to compare the incidence of asbestos bodies in cases of diffuse mesothelioma of pleura and peritoneum diagnosed in the Royal Victoria Infirmary and in

- Department of Pathology, University of Newcastle upon Tyne. neighbouring hospitals in Tyneside and Wearside. The mesothelioma series will be described in detail in a further communication.

The largest consumer of asbestos in the area is the shipbuilding industry, where it is used mainly as an insulator for boilers, pipes, bulkheads, etc. Asbestos is, however, used in other local industries in the manufacture of products such as floor tiles, brake linings, and mattresses.

\section{Materials and Methods}

Smears were prepared from the lungs of 311 patients aged 15 years or over coming to necropsy in the department of pathology, University of Newcastle upon Tyne. An incision approximately $1 \mathrm{~cm}$. in depth was made in the base of the right lung. the cut surfaces were scraped with a knife, and the exuding fluid was smeared on a standard microscope slide. The smears were allowed to dry, fixed in alcohol, and mounted unstained in DPX under a 20 by $50 \mathrm{~mm}$. coverslip, the area beneath the coverslip being systematically examined. To be accepted as asbestos bodies the following criteria were required: refractility, a pale central fibre, smooth or segmented yellowish encrustation, and clubbed or rounded ends. Many smears contained the "curious bodies" described by Tylecote and Dunn (1931) and by Williams (1934), but these consisted of a black central fibre or spicule encrusted with pale yellow refractile material and were easily distinguished from asbestos bodies. In a few cases smears containing asbestos bodies were stained by the Prussian blue method, when they gave a positive reaction. In a number of smears asbestos bodies were too numerous to be counted direct, and an estimate of the number present was made by taking the mean count in 10 fields taken at random 